Proc. of the International Conference on Mechanochemistry and Mechanical Alloying, Kraków, Poland, June 22-26, 2014

\title{
Geopolymerisation of Mechanically Activated Lignite and Brown Coal Fly Ash
}

\author{
G. $\operatorname{MUCSI}^{a, *}$, Z. MOLNÁR ${ }^{a}$ AND S. KumAR \\ ${ }^{a}$ Institute of Raw Material Preparation and Environmental Processing, University of Miskolc, Hungary \\ ${ }^{b}$ CSIR-National Metallurgical Laboratory, Jamshedpur, India

\begin{abstract}
Geopolymers have been synthesized from mechanically activated lignite and brown coal fly ash. Mechanical activation of fly ash has been carried out using laboratory ball mill. To determine the structural changes in both, the fly ash and the resulted geopolymer, Fourier transform infrared spectroscopy measurements were performed. Isothermal conduction calorimetry method was applied to study the geopolymerisation reactions in mechanically non-activated (raw) and activated fly ash samples. The isothermal conduction calorimetry results showed similar peak intensity for mechanically activated (5-30 min) fly ash samples. However, the intensity of peak for $120 \mathrm{~min}$ milled brown coal fly ash was the highest. The compressive strength of the specimen was found to be dependent on the grinding residence time as well as composition/type of fly ash.
\end{abstract}

DOI: 10.12693 /APhysPolA.126.994

PACS: $81.20 . \mathrm{Wk}$

\section{Introduction}

Fly ash is a pozzolanic finely dispersed residue (mineral matter showing pozzolanic activity) collected in electrostatic precipitators following combustion of coal in coal fired power plants. Particle size distribution of the fly ash depends on minerogenetic composition of the fuel coal fineness of grinding and parameters of the system the fly-ash was collected in.

The chemical and mineralogical compositions of the various (class $\mathrm{C}$ and $\mathrm{F}$ ) fly ash types are very different. Therefore, their application, based on the material composition and reactivity, is diverse. Nevertheless, their reactivity can be improved by mechanical activation leading to increase their application possibilities.

Smekal (1952) [1] defined the term of "mechanical activation" as processes affected by mechanical energy, which increase the chemical reactivity of the system without altering chemical composition. However, there are several states of mechanical activation and the following situations can be distinguished: (i) mechanical dispersion, (ii) surface activation, and (iii) mechanochemical (structural) activation [2].

The primary effect of mechanical activation is the comminution of mineral particles, which results in changes in a great number of physicochemical properties of a particular system. During mechanical activation, the crystal structure of a mineral usually becomes disordered and the generation of defects or other metastable forms can be registered [3]. It has been reported that the application of high energy mills like planetary mills and vibratory mills allow dramatic change of the structure and surface properties of solid materials [4-6].

${ }^{*}$ corresponding author; e-mail: ejtmucsi@uni-miskolc.hu
Research results demonstrated that mechanicallytreated cements show an increase in compressive strength after 28 days and also have a faster process of hydration and shorter setting time. A reduction in median particle size generally results in an increased hydration rate and, therefore, higher early strengths are achieved [7-10].

Geopolymers are amorphous aluminosilicates which can be produced by the reaction between silica and aluminosilicate in alkaline medium $(\mathrm{NaOH}$ and/or $\mathrm{KOH})$. Due to its simple, energy efficient and eco-friendly production method, good durability and mechanical properties of geopolymers can replace conventional materials from low tech application (building industry, waste immobilisation) to high tech industry (ceramics with special properties, composites).

Several materials are suitable for geopolymer production which contains silica and alumina bearing phases, like primary (metakaolin) or secondary (fly ash, steel slag, red mud, etc.) raw materials [11, 12]. Fly ash is a potential raw material for geopolymers, thanks to the significant presence of $\mathrm{SiO}_{2}$ and $\mathrm{Al}_{2} \mathrm{O}_{3}$ as the main components [13].

The aim of the present research is to study the effect of mechanical activation on the reactivity of two types (lignite and brown coal) fly ash samples during geopolymerisation and to examine the relation between fly ash fineness and geopolymer compressive strength.

\section{Materials and methods}

\subsection{Materials}

Two types of fly ash samples were used, i.e. a lignite (Mátra Power Station - Visonta) and a brown coal (Tiszaújváros dumpsite) ones. The chemical composition of both samples can be found in Table I.

Main mineral phases identified in both raw fly ash samples were quartz, mullite, cristoballite, quartz, 
TABLE I using distilled water as dispersing media and sodium-

Chemical composition of fly ash samples for main components. L.O.I. - loss on ignition

\begin{tabular}{l|c|c|c|c|c|c|c|c|c}
\hline \hline $\begin{array}{l}\text { Fly } \\
\text { ash }\end{array}$ & $\mathrm{SiO}_{2}$ & $\mathrm{Fe}_{2} \mathrm{O}_{3}$ & $\mathrm{Al}_{2} \mathrm{O}_{3}$ & $\mathrm{CaO}$ & $\mathrm{MgO}$ & $\mathrm{Na}_{2} \mathrm{O}$ & $\mathrm{K}_{2} \mathrm{O}$ & $\mathrm{SO}_{3}$ & L.O.I. \\
\hline $\begin{array}{l}\text { brown } \\
\text { coal }\end{array}$ & 61.32 & 4.27 & 26.71 & 1.50 & 0.89 & 1.06 & 1.72 & 0.25 & 1.92 \\
lignite & 45.85 & 12.05 & 16.82 & 12.97 & 2.90 & 0.50 & 1.83 & 3.76 & 2.25
\end{tabular}

maghemite, anhydrite and albite. The amorphous content for lignite and brown coal fly ash was $52 \%$ and $70 \%$, respectively. The moisture content of lignite fly ash was very low $(0.27 \%)$ in comparison to brown coal one which was significantly higher (17.3\%).

\subsection{Mechanical activation}

The mechanical activation experiments under dry condition were carried out in a conventional tumbling laboratory ball mill with the size of $303 \times 305 \mathrm{~mm}^{2}$ (length $\times$ diameter) minternal diameter (smooth walled), with steel balls (maximal ball size $50 \mathrm{~mm}$ ) as grinding media. The mill filling ratio of the grinding media was $30 \mathrm{~V} / \mathrm{V} \%$, the material filling ratio was $110 \mathrm{~V} / \mathrm{V} \%$ (related to the pore volume of the grinding media). The operating revolution number to critical revolution number (e) was $80 \%$. Residence time of mechanical activation was $5,10,20,30$, and $60(120) \mathrm{min}$. The mechanical activation was carried out until the same fineness (in median particle size) for both samples.

\subsection{Geopolymerisation}

Geopolymer specimens were made by mixing raw or ground fly ash and alkaline activator $\mathrm{NaOH}(6,8,10$, and $12 \mathrm{M}$ ) solution using 0.67 liquid/solid ratio. The paste was placed into pre-oiled moulds and compacted by vibration. The compacted paste was kept in moulds for $24 \mathrm{~h}$ at ambient temperature followed by heat curing at $90^{\circ} \mathrm{C}$ for $6 \mathrm{~h}$. After heat curing the specimens were cooled down to ambient temperature. The mechanical test was carried out by Compression Testing Machine at the age of 7 days.

\subsection{Characterization}

The chemical composition of raw samples was measured by a Rigaku Supermini X-ray fluorescence spectrometer apparatus.

The mineral composition of the raw fly ash was determined by a Bruker D8 Advance XRD powder diffractometer $\left(\mathrm{Cu} K_{\alpha}\right.$ radiation, $40 \mathrm{kV}, 40 \mathrm{~mA}$. Quantitative evaluation was made by Rietveld fitting method on TOPAS3 software using FPM based instrument convolution.

The particle size distribution (PSD) of the raw and the ground materials was measured by HORIBA LA$950 \mathrm{~V} 2$ laser diffraction particle size analyzer in wet mode pyrophosphate as dispersing agent applying the Mietheory as evaluation method. The specific surface area (SSA) was calculated using PSD data by the laser sizer software.

Moisture content $(n)$ was measured by weight difference after drying the sample in an oven at $105^{\circ} \mathrm{C}$ until constant mass was achieved.

The structure of the fly ash and the geopolymer product was investigated by the Fourier transform infrared (FTIR) method. Stretching and bending vibrations of chemical bonds in samples were induced by infra range electromagnetic waves detected by JASCO FTIR 4200 type Fourier transform infrared spectrometer in reflection mode. Three tests were carried out parallel from each sample $\left(4 \mathrm{~cm}^{-1}\right.$ resolution number $)$.

Heat evolution $(\mathrm{d} q / \mathrm{d} t)$ measurements during geopolymerisaton were carried out by eight channel isothermal conduction calorimeter (TAM AIR, Thermometric AB, Jarafalla, Sweden). Seven grams of fly ash was mixed with $7 \mathrm{ml}$ of $6 \mathrm{M} \mathrm{NaOH}$ activator solution. Activator solution was prepared by the dissolution of $\mathrm{NaOH}$ flakes in distilled water at least $24 \mathrm{~h}$ before calorimetric measurements. Measurements were taken at $60^{\circ} \mathrm{C}$.

\section{Results and discussion}

\subsection{Mechanical activation}

The grinding kinetics of the fly ash samples in a tumbling ball mill can be seen in Fig. 1. The brown coal fly ash represents coarser feed particle size distribution $\left(x_{50}=100.01 \mu \mathrm{m}\right)$ than that of the lignite one $\left(x_{50}=52.04 \mu \mathrm{m}\right)$. Significant particle size reduction was observed in both cases. No aggregation of the fine fraction was seen even after 120 min grinding time of brown coal fly ash.

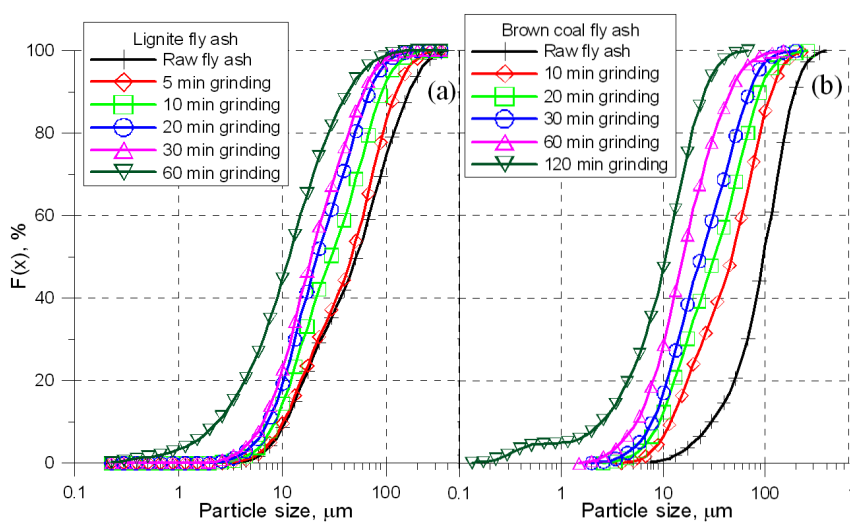

Fig. 1. Particle size distribution of (a) lignite and (b) brown coal fly ash.

Figure 2 shows the variation of the median particle size $\left(x_{50}\right)$ of the two fly ash samples as a function of the grinding time. It was found that logarithmic function can describe the above relation. The equations and the coefficients of determination (R-squared) can be seen in 
Table II. The good fitting was proved by a very high value of the R-squared, namely 0.98966 and 0.998099 for the lignite and brown coal fly ash, respectively.

TABLE II

Fitting results of median size - grinding time relation.

\begin{tabular}{c|c|c}
\hline \hline Fly ash & Equation & R-squared \\
\hline lignite & $\ln (Y)=-0.52 \ln (X)+4.61$ & 0.98966 \\
brown coal & $\ln (Y)=-0.61 \ln (X)+5.25$ & 0.998099
\end{tabular}

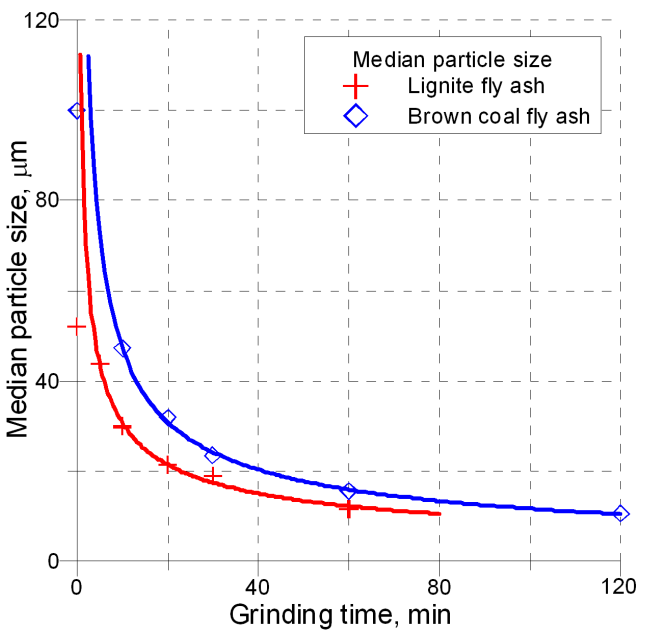

Fig. 2. Variation of median particle size of fly ash samples as function of grinding time.

Almost similar fineness was reached as a result of fine grinding in both cases. The final grinding fineness of the fly ash samples was $11.6 \mu \mathrm{m}$ (60 min, lignite) and $10.62 \mu \mathrm{m}$ (120 min, brown coal). Lignite fly ash size decreased faster than that of the brown coal fly ash one, probably due to the lower composition of the hard components of $\mathrm{SiO}_{2}$ and $\mathrm{Al}_{2} \mathrm{O}_{3}$ (Table I). A good correlation between chemical composition and grindability was found.

FTIR measurements were carried out to monitor the change of fly ash structure during grinding (not presented in this paper). It can be stated that the increasing grinding time of brown coal fly ash resulted in higher peak intensities, which can be associated with structural changes. The intensities of the ground lignite fly ash (10, 30 , and $60 \mathrm{~min}$ ) showed very similar values to each other. However, compared to the raw fly ash spectra, the intensity of the activated fly ash increased significantly.

\subsection{Geopolymerisation}

The process of geopolymerisation was monitored using FTIR and isothermal conduction calorimetry (ICC) analysis. Regarding to the results of the FTIR spectroscopy, new peaks appeared due to geopolymerisation (at 3225 and 3375, 1644 and 1651, 1387 and 1415, 891 and $877 \mathrm{~cm}^{-1}$ for brown coal and lignite fly ash, see Figs. 3 and 4) and other shifted to lower wavenumber (989 and $957 \mathrm{~cm}^{-1}$ ) and changed its intensity.

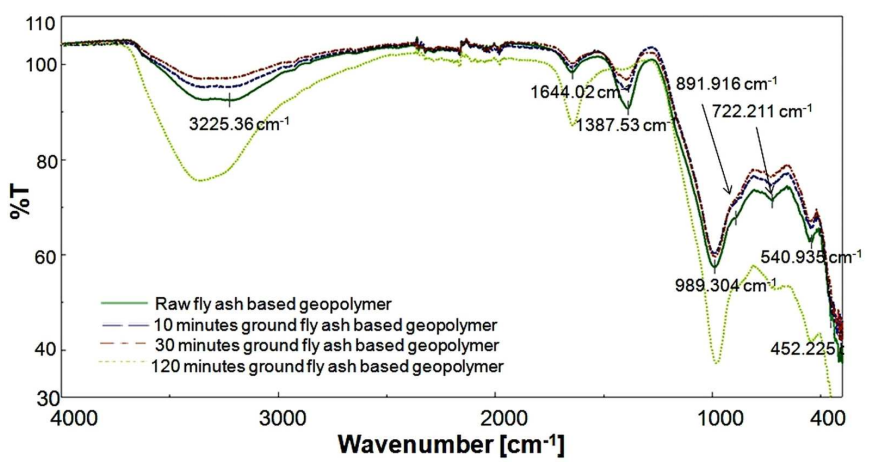

Fig. 3. Brown coal fly ash based geopolymer.

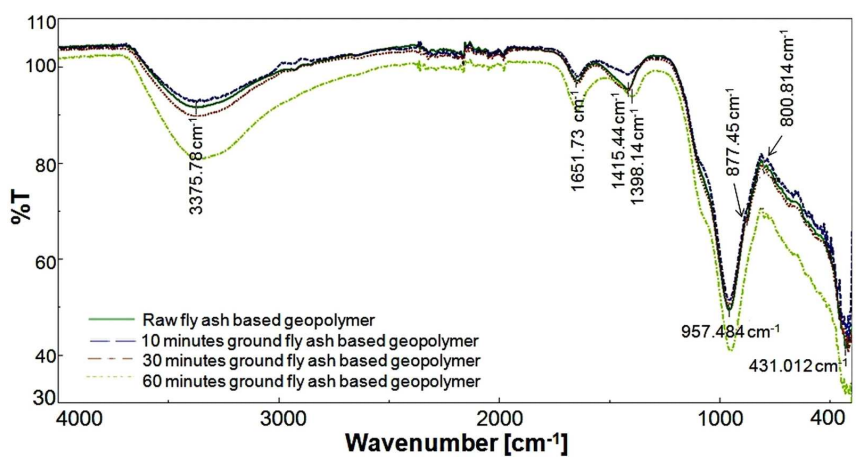

Fig. 4. Lignite fly ash based geopolymer.

Peaks at 3225 and $3375 \mathrm{~cm}^{-1}$ correspond to $-\mathrm{OH}$, $\mathrm{HOH}$ bonds stretching vibration, at 1644 and $1651 \mathrm{~cm}^{-1}$ to $\mathrm{HOH}$ bonds bending vibration, while at 891 and $877 \mathrm{~cm}^{-1}$ are related to $\mathrm{Si}-\mathrm{O}$ stretching and $\mathrm{OH}$ bending bond vibrations $(\mathrm{Si}-\mathrm{OH})$. Peaks at 1387 and $1415 \mathrm{~cm}^{-1}$ correspond to $\mathrm{O}-\mathrm{C}-\mathrm{O}$ stretching vibration.

Peaks observed at $1041 \mathrm{~cm}^{-1}$ and $1012 \mathrm{~cm}^{-1}$ in the case of brown coal and lignite fly ash shift to lower wavenumber $\left(989 \mathrm{~cm}^{-1}\right.$ and $\left.957 \mathrm{~cm}^{-1}\right)$ after geopolymerisation, indicates structural reorganization. It is associated with dissolution of amorphous phase of fly ash in strong alkali media [14].

Higher peak intensities were observed as a function of increasing grinding time indicating higher rate of geopolymerisation [15]. Contrary to this, the FTIR spectra of geopolymerised raw, 10 and 30 min ground brown coal fly ash were very close to each other. Only the peaks intensity of 120 min ground one was significantly higher (Fig. 3). A similar trend was observed in the case of geopolymerised lignite fly ash. The raw, 10 and 30 min samples behave similarly, and the 60 min ground one was remarkably different (Fig. 4). It indicates that the finest fly ash sample resulted in the highest geopolymerisation rate.

Well marked difference in the spectra of the geopolymerised brown coal fly ash may be seen at $1387 \mathrm{~cm}^{-1}$. The geopolymer from 120 min ground fly ash shows very small intensity of the peak in this region (Fig. 3). This is due to formation of less carbonate bond. Due to higher milling time, fly ash has achieved finest particle size and 
highest reactivity, which consequently resulted into better geopolymerisation reaction and left little free alkali to form carbonate. Additionally, it can be seen in Fig. 4 that the peak at $1415 \mathrm{~cm}^{-1}$ shifted to lower position $\left(1398 \mathrm{~cm}^{-1}\right)$ in the case of the final fineness (60 $\left.\mathrm{min}\right) \mathrm{com}-$ pared with other geopolymer products made of coarser fly ash.

To study the effect of fly ash fineness on geopolymerisation mechanism, ICC was used at a temperature of $60^{\circ} \mathrm{C}$. Figure 5 shows the heat evolution curve of the brown coal fly ash geopolymer obtained for $21 \mathrm{~h}$ and of the lignite fly ash sample obtained for $22 \mathrm{~h}$.

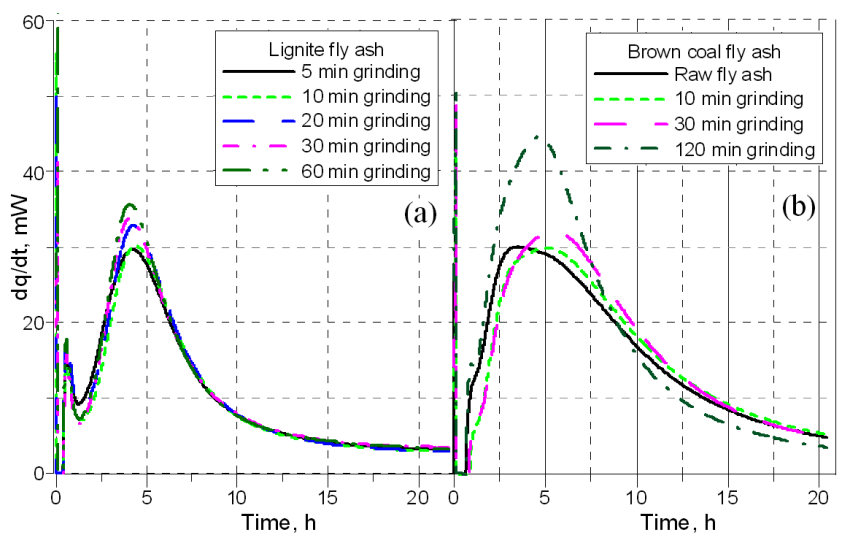

Fig. 5. ICC results of (a) lignite and (b) brown coal fly ash.

Three exothermic peaks were observed in both raw and ground products. After wetting and starting dissolution reaction, a short induction period can be observed during 30-120 min, presumably due to low reactivity of fly ash. This was followed by an exothermic peak related to dissolution-precipitation reaction and formation of hydrated aluminosilicate gel phase. The third peak corresponds to geopolymerisation reaction. The increasing grinding time resulted in the enhance of the last exothermic peak intensity (Fig. 5a), the 5 min ground fly ash has peak maximum at $29.6 \mathrm{~mW}$ after $4 \mathrm{~h} 6 \mathrm{~min}$, while the 60 minutes ground fly ash reaches the maximum at $35.64 \mathrm{~mW}$ after $4 \mathrm{~h} 4 \mathrm{~min}$, indicating a $21 \%$ increase.
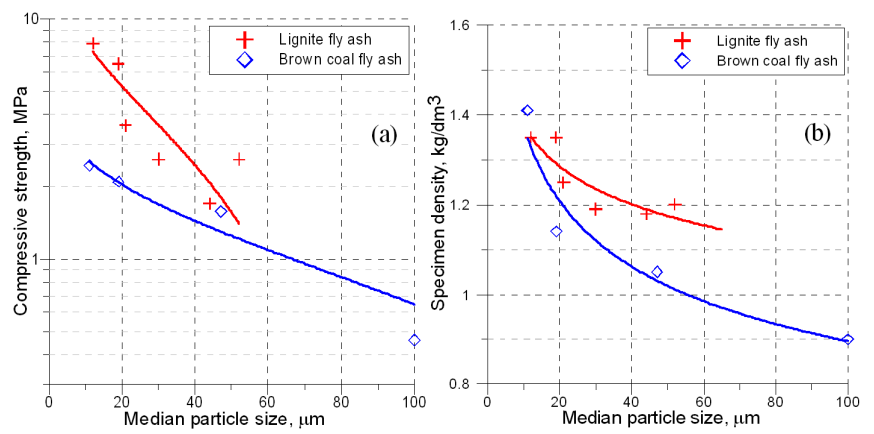

Fig. 6. Relation between characteristic particle size $x_{50}$ and (a) geopolymer compressive strength and (b) specimen density.
In case of brown coal raw fly ash (Fig. 5b), the third peak reached earlier, but its intensity was relatively low. It is probably due to that geopolymer reaction, ended before the final hardened structure, could be formed, because the raw fly ash had low reactivity. The low compressive strength of geopolymerised raw fly ash confirms this statement (Fig. 6a). The generation of the highest heat $(44.5 \mathrm{~mW})$ was found to be after 4 hour $36 \mathrm{~min}$ in the case of 120 min ground brown coal fly ash (Fig. 5a), meaning $47 \%$ improvement. The maximum rate of heat evolution increased with increasing fineness in both fly ash samples.

\subsection{Effect of mechanical activation on geopolymer compressive strength}

In order to compare the geopolymer properties and raw material characteristics, the median particle size and geopolymer compressive strength relation was determined (Fig. 6). The same trend was observed in the lignite as well as brown coal fly ash based geopolymer. Finer median particle size resulted in higher compression strength. However, the lignite fly ash geopolymer showed a steeper curve and compressive strength increased by more than $300 \%$ due to the mechanical activation of fly ash. The strength of the brown coal fly ash based product enhanced by more than $500 \%$ higher after grinding. Similar trend was found in the relation of median size and specimen density (Fig. 6b). The results indicate that the finer particle size distribution of the raw material leads to the higher specimen density of the geopolymer which refers to higher compressive strength.

It was found, according to the FTIR, ICC and compressive strength results, that mechanical activation of both fly ash samples for 60 and 120 min leads to significant structural changes, which affected the compressive strength in their geopolymerised products. However, as can be seen in Fig. 6, the higher specimen density (a more compact structure) and higher specific surface area are responsible as well for strength improvement in the case of coarser fly ash.

Beside the mechanical activation, the effect of chemical activation was investigated as well (Fig. 7). In this measurement series the effect of $\mathrm{NaOH}$ concentration of alkaline activator was studied as function of compressive strength.

As a result of the concentration effect of the $\mathrm{NaOH}$ on the compressive strength of the different fly ash based geopolymer product, it was found that brown coal fly ash indicated a monotonous increasing curve reaching the maximum of $10.2 \mathrm{MPa}$ at $12 \mathrm{M}$. It means that the mechanical activation liberated the $\mathrm{SiO}_{2}$ and $\mathrm{Al}_{2} \mathrm{O}_{3}$ species which can take part in the geopolymerisation reaction resulting in a stronger structure. However, the curve of the lignite fly ash based product has a maximum point of $12.3 \mathrm{MPa}$ at $10 \mathrm{M}$. It is contrary to the literature data. The main explanation might be that the newly formed geopolymer structure damaged due to high alkaline conditions (unreacted $\mathrm{NaOH}$ ). 


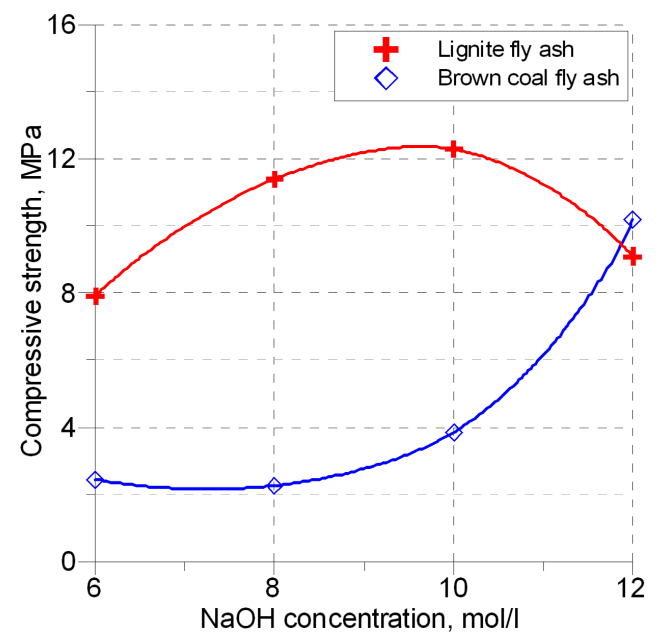

Fig. 7. Variation of compressive strength of geopolymer as function of $\mathrm{NaOH}$ concentration.

\section{Conclusions}

As a result of the investigation the effect of mechanical activation on fly ash characteristics and on the geopolymerisation was revealed. Furthermore, difference in strength development was observed between the activated fly ash samples.

The relation of grinding time and median size of fly ash can be described by logarithmic function. The FTIR investigation of geopolymer specimens shows new peaks. The shifting of peak position is due to structural changes and amorphous aluminosilicate gel formation. Increasing reactivity of brown coal fly ash demonstrated by FTIR spectra of its geopolymers. Peak belonging to $\mathrm{O}-\mathrm{C}-\mathrm{O}$ bonds (related to the presence of carbonate from unreacted activator solution) shows lower intensity in case of fly ash with higher specific surface area based geopolymer due to better alkali activator consumption in geopolymerisation process, which is associated with higher reactivity of the finer fly ash.

Based on ICC measurements, due to the increasing fineness the exothermal peaks maxima also increased in both cases. However, the increasing rate of brown coal fly ash was higher.

A relationship was found between the geopolymer physical properties (compressive strength, density) and fly ash fineness (median particle size). The compressive strength of the geopolymer can be reasonably controlled by grinding process.

\section{Acknowledgments}

The research work was performed in the framework of a TÉT Indo-Hungarian collaboration project entitled "Tailoring of fly ash based geopolymer properties by mechanical activation (GEOPOL10)" at the Centre of Excellence in Sustainable Natural Resource Management at the Faculty of Earth Science and Engineering, University of Miskolc. The authors greatly appreciate for the mineralogical and strength investigation for the Institute of Mineralogy and Geology and the Institute of Mining and Geotechnics, respectively.

\section{References}

[1] A.G. Smekal, in: Proc. Int. Symp. on the Reactivity of Solids, Ed. J.A. Hedvall, Elanders, Gotenburg 1952.

[2] A.Z. Juhász, L. Opoczky, Mechanical Activation of Minerals by Grinding, Akadémiai Kiadó - Ellis Horwood Ltd Publ., Budapest 1990.

[3] P. Balaz, M. Achimovicová, Hydrometallurgy 84, 60 (2006).

[4] P. Baláz, Extractive Metallurgy of Activated Minerals, Elsevier, Amsterdam 2000, p. 278.

[5] É. Kristóf-Makó, A.Z. Juhász, Thermochim. Acta 342, 105 (1999).

[6] K. Tkácová, Mechanical Activation of Minerals, Elsevier, Amsterdam 1989, p. 293.

[7] G. Frigioine, S. Marra, Cement Concrete Res. 6, 113 (1976).

[8] B. Osbaeck, V. Johansen, J. Am. Ceram. Soc. 72, 197 (1989).

[9] M. Senna, Izv. Sib. Otd. Akad. Nauk SSSR, Ser. Chim. Nauk 2, 3 (1985).

[10] S. Wakasugi, K. Sakai, S. Shimobayashi, H. Watanabe, in: Concrete under Severe Conditions, Vol. 2, Ed. O.E. Gjorv, E \& FN Spon, London 1998, p. 2161.

[11] K. Komintsas, D. Zaharaki, Miner. Eng. 20, 1261 (2007).

[12] G. Mucsi, J. Lakatos, Z. Molnár, R. Szabó, in: The 9th Int. Conf. "Environmental Engineering": Book Series: Int. Conf. on Environmental Engineering (ICEE) - Selected Papers, Vilnius, 2014, Vilnius Gediminas Technical University, 2014, Paper 39.

[13] J. Davidovits, Geopolymer Chemistry and Application, Institut Geopolimére, Saint-Quentin (France) 2011.

[14] D. Panias, I. P. Giannopoulou, T. Perraki: Coll. Surf. A 301, 246 (2007).

[15] S. Kumar, R. Kumar, Ceram. Int. 37, 533 (2011). 